\title{
Analysis of the effect of Propeller Slip Flow on Flight
}

\author{
Xiujuan Liu' ${ }^{1, a}$, Chunguang Wang ${ }^{2, a}$, Song Li, ${ }^{3, a}$, Yuankai Li ${ }^{4, a}$, Luofeng Lin ${ }^{5, a}$ \\ Aviation University of Air Force, Changchun, China \\ 723704537@qq.com
}

Keywords: Propeller; flight; propeller slip flow

\begin{abstract}
In view of the negative effects caused by propeller slip flow on flight, this paper used momentum theory combined with finite cubage to find the solution to N-S equation and numerical analogue and also analized propeller procession and disturbance of propeller slip flow to the flow field. Finally the dynamic change and control theory were put forward.
\end{abstract}

\section{Introduction}

Propeller is the role of the engine power becomes effective power driven aircraft forward. However, the propeller during operation, will produce some side effects, to adversely affect the flight. Dry aircraft designer, at the beginning of the design phase is necessary to study the propeller by means of computational and experimental aerodynamic characteristics and interference effect between the various parts of the body. And other power plant (turbojet engine) compared to interfere with the propeller has a great influence on the aircraft's aerodynamic layout, this effect even decisive. Interference is the most important influence on the propeller slipstream swept parts, mainly impact on the wings and tail. In this paper, the theory of finite volume method momentum N-S method for solving equations to study the propeller slipstream effect on aircraft flying.

Propeller procession theory. Propeller procession theory, the propeller is vital to generate tension, propeller blade tension by pulling each constituted. Because the cross-sectional shape of the wing profile blade similar, so propellers pull the truth, too, and the wings produce lift essentially the same reason. Propeller Rally Rally is not only positive, and negative tension. About two tension following form.

Propeller positive tension.Propellers pull, each blade by pulling posed. Because the cross-sectional shape of the wing profile blade similar, so propellers pull the truth, too, and the wings produce lift essentially the same reason.Because of the similarity of the cross-sectional shape of the propeller blade airfoil wing, the relative air flow over the front face of propeller blades, the same as on the surface of the wing flows through the flow tube thinning, flow speed, pressure drop; relative airflow after flowing through the propeller blade surface, like through the lower surface of the wing, as the flow tube thicker, slow flow rate, pressure. Paddle blade surface forming the front and rear pressure difference, the pressure difference is the total sum of the aerodynamic blade $(\mathrm{R})$.

Total aerodynamic blades can be decomposed into two components (Figure 1): a propeller shaft parallel, said tension P; and the other perpendicular to the axis paddle, propeller rotation obstruction, said rotational resistance $\mathrm{Q}$.

Rally propeller can be calculated.

$$
\begin{aligned}
& d R=C_{r} \rho \frac{W^{2}}{2} d S \\
& P=C_{P} \rho n^{2} D^{4}
\end{aligned}
$$

$C_{P}$ - pull factor, which represents the integrated blade angle, impact forward ratio, the shape of the blade, the flight number and M Reynolds and other factors on the rally, the size is determined by experiment. 


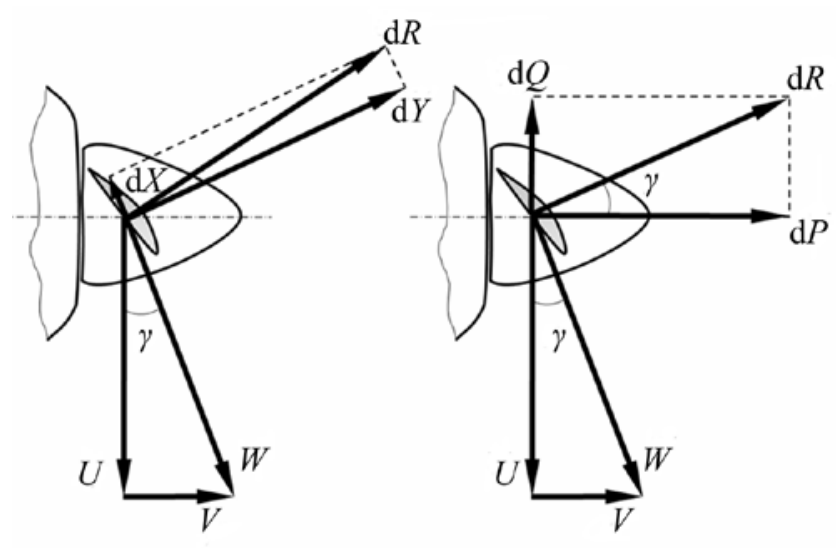

Fig.1 Aerodynamic blades and component

Propeller negative pull.Propeller aerodynamics have a prominent feature, is in a condition, the propeller can have a huge negative tension. In the landing roll, the use of negative tension generated by the propeller, can shorten the landing roll distance; but in the air, 'once produced large negative tension, it will make a sharp slowdown in aircraft and seriously undermine the balance of the aircraft. Therefore, understanding the negative variation produces and tension, for the proper use of the power plant, has an important role to ensure flight safety.

The blade angle of attack is small or negative angle of attack, the pressure greater than the pressure in front of the rear propeller plane propeller plane, air force after pointing upward. In this case, parallel to the rear propeller shaft of the force point, a negative tension; component perpendicular to the pitch of the propeller shaft to prevent rotation of the turbine at this time still driven propeller rotates, the propeller of the effective power reduction. Air start pulling negative size, starting with the flight altitude, and speed. The closer the starting speed governor to control the speed or lower the height, the greater the negative pull.

Wing propeller slipstream flow field disturbance.Early estimates for the momentum theory propeller slipstream disc at a speed and speed, propeller efficiency and other parameters, the classical continuity equation, simplified derivation of momentum and energy equations derived. The momentum theory combined with computational fluid dynamics, which can achieve a certain purpose of simplifying the workload, the results can be obtained some initial estimate can not get. This calculation is used in the momentum theory with the Finite Volume Method for the Simulation wing propeller slipstream interference flow field. With respect to the modeling done directly on the propeller blade grid computing, the advantage of this method is to simplify the mesh generation, shortening the computation time, the disadvantage is the details on the propeller can not be accurately simulated. This article focuses on the slipstream effect on the belt wing trailing edge flaps, propeller problem could be simplified details. The equation used to calculate a three-dimensional integral form of N-S Reynolds averaged equations.

Propeller slipstream effect on aircraft flying.After calculation and experiment, during takeoff state of decline Flow on wing lift efficiency is calculated as 0.15 Mach number, Reynolds number of $1.8 \times 107$. To compare the influence of the propeller slipstream, the need to add a slip stream of the wing is not calculated to ensure the quality of the mesh grid generation using point docking and face lap. In the propeller simulation, using a quadratic function distribution sudden supercharged intensity distribution, not taken into account the impact of man rotation, although the real impact of the propeller has a gap, but the research wing or even slipstream the whole machine aerodynamic characteristics, or have some reference value.

From Fig. 2, 3, and 4 can be drawn, the propeller slipstream effects for wing lift is able to play the role, obviously, in the slipstream of the role of regional, or whether it is the host wing flap pressure area coefficient included larger, namely the lift coefficient larger. From the above chart data can be drawn with respect to the main wing, the slipstream of the flap has a greater impact, increasing the lift coefficient of the three sectional flap intercepted this calculation is greater than $100 \%$, slippery inner 
flow flap lift coefficient increase was 149.44\%; 135 13\%; 156.15\%. The increase in the main wing of the three sectional lift coefficient were $47.41 \%$, $44.60 \%$ and $44.25 \%$.

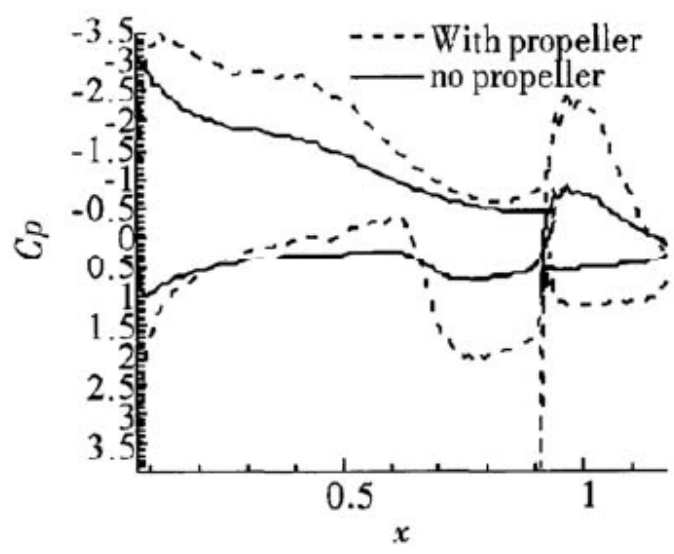

Fig.2. $24.17 \%$ plus exhibition strengths main wing flaps sectional

Have Slipstream pressure distribution

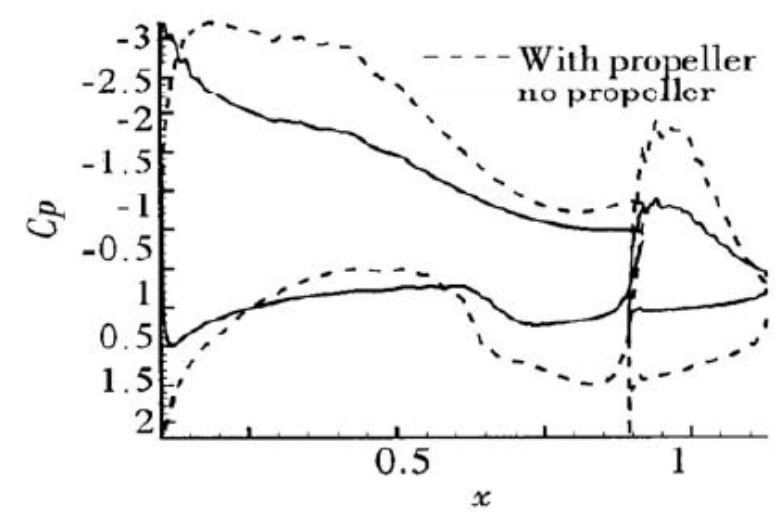

Fig.3.32.50\% plus exhibition strengths main wing flaps sectional

Have Slipstream pressure distribution (propeller slipstream at the center of the area)

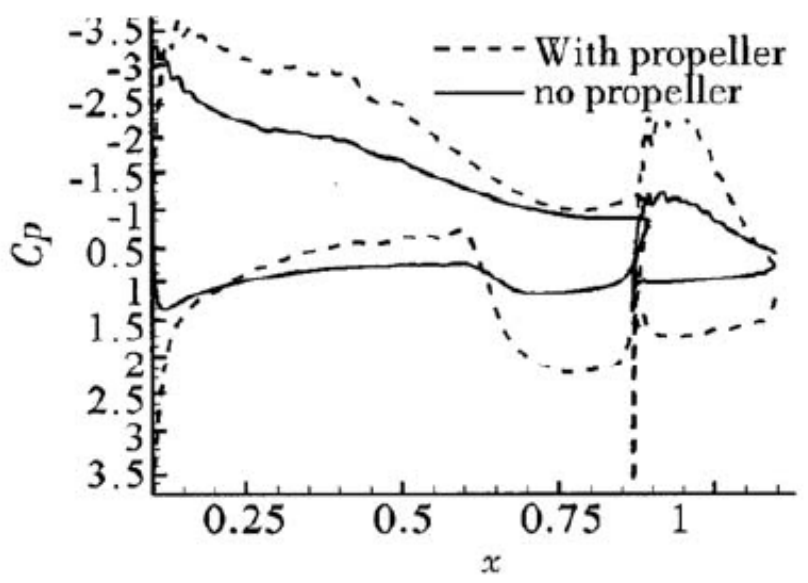

Fig.4.40.83\% plus exhibition strengths main wing flaps sectional Have slip

(Slip stream flow pressure distribution area slipstream is greatest)

Figure 5 is whether the change in the propeller slipstream effect of wing lift coefficient with angle of attack of the diagram, the angle of attack range of 2 degrees to 16 degrees, it can be seen from the figure, the propeller slipstream to the wing at different angles of attackThey can play a role in boosting. Although the slip stream effect, the wing is also a corresponding increase in the resistance, but people are concerned about the increase lift coefficient, some resistance increase is acceptable. 


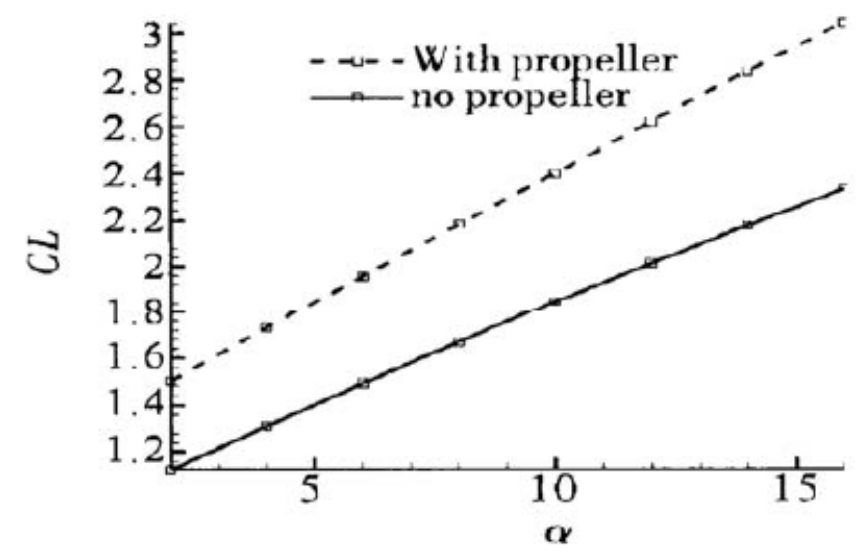

Fig.5 Have slipstream lift coefficient curve comparison

\section{Summary}

The momentum theory with finite volume method for solving the equation N-5 method, numerical simulation can take off under better state, propeller slipstream interference with the wing trailing edge flaps aerodynamic characteristics. This method has important applications in engineering, can provide theoretical support for propeller aircraft design.

In the take-off state, propeller slipstream can be greatly improved with the trailing edge of the wing flap lift.

Nested grid method on the paddle plate meshing used, to ensure paddle plate and wing mesh quality of the premise, can greatly reduce the difficulty of the mesh generation, and does not affect the final numerical results.

Further refinement of the method, the need to influence the rotation speed of the propeller slipstream join calculated using this method is used to analyze the propeller slipstream effect on the aerodynamic characteristics of the whole machine.

Through theoretical analysis of the propeller slipstream, understand their impact lateral forces and moments on aircraft, and clearly recognized the propeller slipstream on engine power relations, learn to use the lever rudder eliminate slipstream effect on aircraft in flight form their own manipulation habits.

\section{References}

[1] ZhouSheng.Air propeller and propeller fan [M] Beijing: National Defense Industry PressReference to a book:

[2] ZhaoXX., Propeller slip test research on the impact of traffic flow around the aircraft[J].

[3] LiZhengChu. Propeller slipstream on wing flow field Experimental study on the impact[J].

[4] ChenZhengCai. Propeller slipstream - numerical wing interference effects.China Aerodynamics Research and Development Center .1980

[5] Propeller slipstream impact research group. Slipstream affect propeller mechanism. 1995 